\title{
Design of a Wire Cut EDM End-Effector with Strict Robotic Constraints
}

\author{
Sergio ALMEIDA ${ }^{\mathrm{a}, 1}$, John P.T. MO ${ }^{\mathrm{a}}$, Cees BIL ${ }^{\mathrm{a}}$, Songlin DING ${ }^{\mathrm{a}}$, Xiangzhi WANG $^{\mathrm{b}}$ \\ a School of Engineering, RMIT University, Melbourne, VIC 3083, Australia \\ ${ }^{\mathrm{b}}$ Nanjing University of Aeronautics and Astronautics, Qinghai, Nanjing 210016, P.R \\ China
}

\begin{abstract}
Wire Electric Discharge Machining (WEDM) stands out as a noncontact and nearly force-free machining technique able to cut complex workpieces, delivering dimensional accuracy and superior surface finishing, especially for exotic super-hard materials. On the other hand, machining with six-axis industrial robots (IR) has received much attention due to its notorious advantages over CNC machines to deliver cost efficiency, large envelope, and complex tool kinematics. However, robot machining suffers from severe limitations regarding the tool payload, chatter, repeatability, accuracy error, complex programming and frequently poor surface finishing. This paper investigates the benefits of combining a robot with WEDM to exploit the advantages of both techniques. However, the new system design is not trivial and will involve a transdisciplinary approach and inventive problem solving to design and control a WEDM endeffector. The present study adopts the TRIZ algorithm approach to design a novel WEDM end-effector and define actions to be taken to achieve a flexible and accurate robotic machining system for hard-to-cut materials.
\end{abstract}

Keywords. Wire Electric Discharge Machining, Robotic WEDM machining, WEDM end-effector, TRIZ, transdisciplinary design

\section{Introduction}

Technological progress has pushed the boundaries of materials and design. The demand for high-performance materials such as superalloys, composites, ceramics, semi and superconductors are a hot topic. However, the same properties that make these materials appropriate for high-end applications imposed significant cutting challenges while using traditional machining techniques [1]. As a solution, electric discharge machining (EDM) has been successfully adopted to cut any hard material offering at least $0.01 \mathrm{~S} / \mathrm{cm}$ of electric conductivity [2]. The process consists of an electrode steering a series of high-frequency electric discharges that gradually melts the workpiece's surface into small particles flushed by the dielectric fluid. In EDM, there is no contact between the electrode and the workpiece and nearly no forces. Thus, stresses, chatter and vibrations from traditional machining can be avoided. Up to the present day, to control the electrode path, EDM is configured on computer numerically controlled (CNC) machines. However, CNC machines are designed for stiffness to cope with the high forces and vibration of traditional machining. As a result, $\mathrm{CNC}$ has a limited working envelope that frequently leads the workpiece to be segmented in

\footnotetext{
${ }^{1}$ Corresponding Author, Mail: s3703963@student.rmit.edu.au.
} 
multiple stages, demanding tricky fixtures, resulting in lower precision and additional costs [3].

To overcome $\mathrm{CNC}$ limitations, traditional machining using 6-axis industrial robots (IR) have been extensively investigated, looking for cost-efficiency and design freedom [4]. Besides, since IRs can attach a plethora of different end-effector tools (EE), sensors and control mechanisms, IRs can deliver multi-functionality with improved productivity [5]. Nevertheless, due to IR's intrinsic design, they lack stiffness and cannot hold heavy loads either cope with high forces of traditional machining, particularly on exotic hard-to-cut material. That is why most of the correlated research efforts focus on solving IR machining problems originated from the lack of IR stiffness resulting in machining vibration, poor surface finishing, lack of precision and repeatability [6].

On the other hand, the EDM process, particularly wire EDM (WEDM), has been suggested as a promising solution for IR lack of stiffness and limited forces [7]. Other technical obstacles persist and are fundamentally spread by their transdisciplinary nature. Among the most notorious, the following are a few: limited payload, complicated programming, accuracy error, and complex control. Therefore, the present research will adopt the Theory of Inventive Problem Solving (TRIZ) algorithms to find conceptual transdisciplinary engineering solutions to design a WEDM end-effector with strict robotic constraints. The research is organised as follows. Section 2 describes the methodology. Section 3 presents the results, and lately, section 4 is the conclusion.

\section{Methodology for End-Effector design by TRIZ}

Initially developed by G.S. Altshuller in the 1940s, the technique of TRIZ has been exploited more fully in the 1990s. It consists of algorithms and 40 transdisciplinary principles for driving creative thinking on problem-solving, rather than an intuitive and monodisciplinary trial and error approach. Therefore, the first step in our methodology is to map the usual problems from IR machining and WEDM to apply the TRIZ approach.

Classical TRIZ have available several different tools whose selection depends on the problem and context, making it challenging to select the appropriate tools. To properly formulate an inventive problem that forms a contradiction and respective application of TRIZ principles, we adopt the algorithm suggested by Cameron [8] to later incorporate the concepts into the WEDM end-effector design. Figure 1 summarises the adopted methodology.

To map the problems and main aims, a systematic review [9] on literature from 2010 to 2020 was conducted from scientific databases as well as patents, industry articles, and reports not included in academic repositories.

\section{Results}

\subsection{Problem mapping on wire EDM and robotic machining}

The literature was tabulated in chronological order to find recurrent problems on WEDM and potential sources of TRIZ contradictions. Next, the problems were classified into identified five main categories of material removal rate (MRR), surface 
roughness (SR), wire break or performance (W.P.), design freedom (D.F.) and dimensional or geometrical error (DGE). Table 1 summarises the findings.

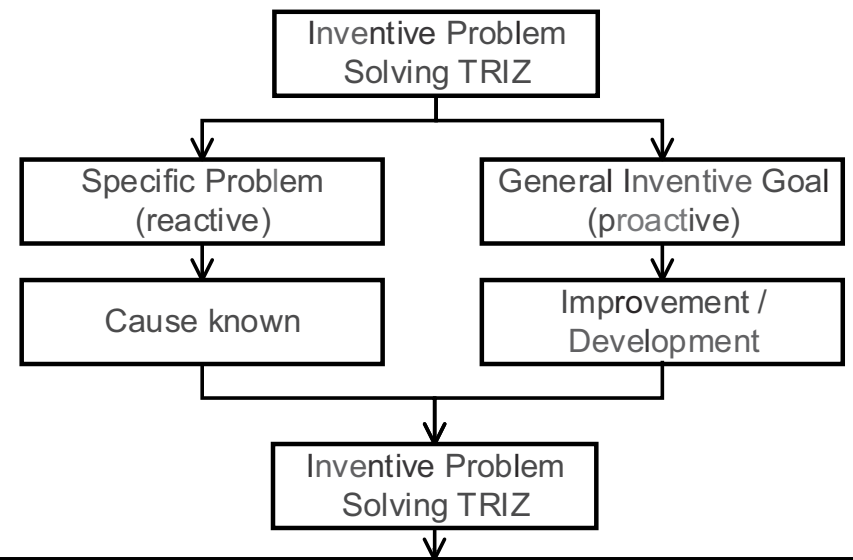

\section{Selected Classical TRIZ Solutions Tools}

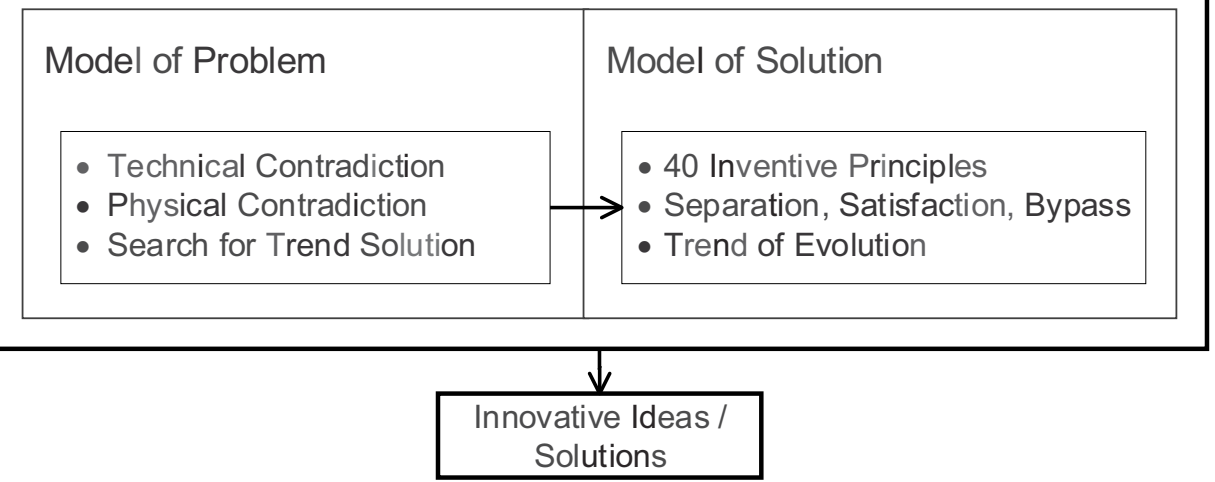

Figure 1. Algorithm for the use of narrowed TRIZ tools.

Similarly, to find recurrent problems on robotic machining and discover potential sources of TRIZ contradictions, the literature was again tabulated in chronological order while robotic machining problems classified into identified four main categories of accuracy, vibration, and compensation and low stiffness. Table 2 summarises the findings.

Table 1. Recurrent aims and problems on WEDM.

\begin{tabular}{|c|c|c|c|c|c|c|c|}
\hline \multirow[b]{2}{*}{$\underset{J}{\grave{J}}$} & \multirow{2}{*}{ 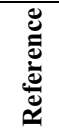 } & \multirow[b]{2}{*}{ Main aim } & \multicolumn{5}{|c|}{ Problem } \\
\hline & & & $\underset{z}{\underline{a}}$ & $\frac{\alpha}{\sim}$ & 3 & 㟔 & 项 \\
\hline 2010 & {$[10]$} & Adaptive fuzzy servo control to avoid wire breakage & $\bullet$ & $\bullet$ & $\bullet$ & & \\
\hline 2012 & {$[11]$} & Process optimisation of aluminium composite & $\bullet$ & $\bullet$ & & & \\
\hline
\end{tabular}




\begin{tabular}{|c|c|c|c|c|c|}
\hline 2013 & 12] & WEDM control to avoid wire rupture in high thickness cut & - & $\bullet$ & $\bullet$ \\
\hline 2014 & [13] & Review on process optimisation & $\bullet$ & $\bullet$ & $\bullet$ \\
\hline 2015 & $\begin{array}{l}{[14]} \\
{[15]} \\
{[16]} \\
{[17]} \\
{[18]} \\
{[19]}\end{array}$ & $\begin{array}{l}\text { Process optimisation for SR based on wire geometry/speed \& } \\
\text { current } \\
\text { Adaptive real-time control for MRR, SR and stability } \\
\text { Process optimisation by adaptive neuro-fuzzy inference } \\
\text { Process optimisation for taper cutting } \\
\text { Adaptive servo control based on current pulse probability } \\
\text { Real-Time control system for MRR }\end{array}$ & & $\bullet$ & $\bullet$ \\
\hline 2016 & $\begin{array}{l}{[20]} \\
{[21]} \\
{[22]} \\
{[23]}\end{array}$ & $\begin{array}{l}\text { Identify the most significant parameter for MRR and SR } \\
\text { Investigate wire movements and workpiece location } \\
\text { Process optimisation for tapered parts } \\
\text { Investigate burning surface in High-speed WEDM parameters }\end{array}$ & & $\bullet$ & $\stackrel{\bullet}{\bullet}$ \\
\hline 2017 & $\begin{array}{l}{[24]} \\
{[25]} \\
{[26]} \\
{[27]}\end{array}$ & $\begin{array}{l}\text { Machining parameters against harmful wire vibration } \\
\text { New wire mechanism for improved SR and M.R. in tapper } \\
\text { Improved accuracy and MRR with ultrasonically activated wire } \\
\text { Adaptive servo control for variable thickness }\end{array}$ & & & $\begin{array}{l}\bullet \\
\bullet \\
\bullet\end{array}$ \\
\hline 2018 & $\begin{array}{l}{[28]} \\
{[29]} \\
{[30]} \\
{[31]}\end{array}$ & $\begin{array}{l}\text { New HS-WEDM with long wire with process parametrisation } \\
\text { Processes optimisation for Titanium Grade } 6 \\
\text { Influence of cut direction in SR } \\
\text { Processes optimisation for angular error in taper cutting }\end{array}$ & & & - \\
\hline 2019 & $\begin{array}{l}{[32]} \\
{[33]} \\
{[34]}\end{array}$ & $\begin{array}{l}\text { Processes optimisation for Al (6082)/tungsten carbide composite } \\
\text { High-performance wire } \\
\text { Investigates different control strategies in wire EDM }\end{array}$ & & & $\ddot{\bullet}:$ \\
\hline 2020 & [35] & Processes optimization for Inconel 625 & $\bullet$ & & \\
\hline
\end{tabular}

Table 2. Recurrent aims and problems on robotic machining.

\begin{tabular}{|c|c|c|c|c|c|c|}
\hline \multirow[b]{2}{*}{$\stackrel{\Xi}{\Xi}$} & \multirow{2}{*}{ 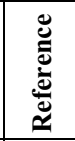 } & \multirow[b]{2}{*}{ Main aim } & \multicolumn{4}{|c|}{ Problem } \\
\hline & & & 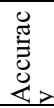 & 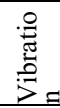 & 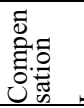 & 焉 \\
\hline$\overline{2010}$ & $\begin{array}{l}36] \\
{[37]} \\
\end{array}$ & $\begin{array}{l}\text { Investigate errors due to tool displacement } \\
\text { Real-time dynamic error compensation }\end{array}$ & $\bullet$ & & $\bullet$ & $\bullet$ \\
\hline 2011 & {$[38]$} & Review on error sources in IR machining & $\bullet$ & - & - & - \\
\hline 2012 & \begin{tabular}{|l|}
{$[39]$} \\
{$[40]$} \\
{$[41]$} \\
\end{tabular} & $\begin{array}{l}\text { Robotic wire cutting process with design freedom } \\
\text { Automated robotic deburring } \\
\text { Real-time compensation control }\end{array}$ & $\begin{array}{l}\bullet \\
\bullet \\
\bullet\end{array}$ & • & $\bullet$ & $\bullet$ \\
\hline 2013 & \begin{tabular}{|c|}
{$[42]$} \\
{$[43]$} \\
{$[44]$} \\
{$[45]$} \\
{$[6]$} \\
{$[46]$} \\
\end{tabular} & $\begin{array}{l}\text { Contact sensing-based for grinding process } \\
\text { Propose CNC-like machining } \\
\text { Multi-process programming } \\
\text { Automated robotic deburring } \\
\text { Map primary sources of IR machining error } \\
\text { Real-time compensation using piezo actuators }\end{array}$ & $\begin{array}{l} \\
\bullet \\
\bullet \\
\bullet \\
\bullet\end{array}$ & • & $\begin{array}{ll} \\
\bullet \\
\bullet \\
\bullet \\
\bullet \\
\end{array}$ & $\begin{array}{l} \\
\bullet \\
\bullet \\
\bullet \\
\end{array}$ \\
\hline 2014 & {$[47]$} & Robot stiffness & - & & - & - \\
\hline 2015 & {$[48]$} & Automatic tool changing system & $\bullet$ & & & \\
\hline 2016 & {$[49]$} & CNC-like machining & $\bullet$ & & & $\bullet$ \\
\hline 2017 & \begin{tabular}{|l|}
{$[50]$} \\
{$[51]$} \\
{$[52]$} \\
\end{tabular} & $\begin{array}{l}\text { Robot stiffness } \\
\text { Wire cutting process } \\
\text { Trajectory (cutting path) for the grinding process }\end{array}$ & $\dot{\bullet}$ & & $\bullet$ & \\
\hline 2018 & $\begin{array}{l}{[53]} \\
{[54]} \\
\end{array}$ & $\begin{array}{l}\text { Geometric design freedom } \\
\text { 3D workpiece into wire cutting program }\end{array}$ & $\bullet$ & & & \\
\hline 2019 & \begin{tabular}{|c|}
{$[55]$} \\
{$[56]$} \\
{$[4]$} \\
\end{tabular} & $\begin{array}{l}\text { Contact sensing-based for grinding process } \\
\text { Real-time control } \\
\text { Literature review IR machining }\end{array}$ & $\begin{array}{l}\bullet \\
\bullet \\
\bullet\end{array}$ & $\bullet$ & $\bullet$ & $\dot{\bullet}$ \\
\hline 2020 & [57] & Evaluate dynamic and static stiffness models for robot pose & $\bullet$ & $\bullet$ & & $\bullet$ \\
\hline
\end{tabular}




\subsection{Transdisciplinary End-Effector conceptualisation by TRIZ}

To conceptualise the end-effector, we focus on two primary sources. First, common problems in both WEDM and Robotic machining. Second, we list those problems with a high probability to occur due to this novel combination. As a result, a list of broad and transdisciplinary causes is found.

Once the problems were identified, TRIZ [8] is adopted to approach the problems and trigger innovative concepts to be later incorporated into the WEDM end-effector design. Table 3 presents the results.

Table 3. Concepts for designing a robotic WEDM end-effector.

\begin{tabular}{|c|c|c|c|}
\hline \multirow{2}{*}{ Problem description } & \multicolumn{3}{|c|}{ TRIZ } \\
\hline & Model problem & Principle & Model solution(s) \\
\hline 1. Wire erosion & $\begin{array}{l}\text { (T.C.) Create intense } \\
\text { erosion without being } \\
\text { eroded }\end{array}$ & \begin{tabular}{|l|} 
- Regeneration \\
- Universalisation
\end{tabular} & $\begin{array}{l}\text { - Debris stick to the wire creating a } \\
\text { protective layer renewed along with } \\
\text { the erosion process. } \\
\text { - Apply graphite brush to provide } \\
\text { electric power and compensate wear by } \\
\text { filling up wire craters. }\end{array}$ \\
\hline 2. Flushing debris & $\begin{array}{l}\text { (T.C.) Travel deep into } \\
\text { the kerf but get out fast }\end{array}$ & $\begin{array}{l}\text { - Mechanical } \\
\text { vibration } \\
\text { - Add a force field }\end{array}$ & $\begin{array}{l}\text { - Use ultrasonic activation to achieve a } \\
\text { stationary wire wave to stabilise and } \\
\text { overcome wire warping. } \\
\text { - The dielectric fluid nozzle is } \\
\text { designed to create a laminar field flow. }\end{array}$ \\
\hline $\begin{array}{l}\text { 3. Servo delay } \\
\text { during short } \\
\text { circuit }\end{array}$ & $\begin{array}{l}\text { (TrE) Move away from } \\
\text { to workpiece and back } \\
\text { with nearly no time }\end{array}$ & - Segmentation & $\begin{array}{l}\text { - Add to the servo system a piezo } \\
\text { actuator able to move high frequency } \\
\text { and microscale only for short-circuit } \\
\text { events. }\end{array}$ \\
\hline 4. Wire tension & $\begin{array}{l}\text { (PhC) Achieve a gravity } \\
\text { field in any direction } \\
\text { allowing robotic freedom } \\
\end{array}$ & \begin{tabular}{|l|} 
- Replace a \\
mechanical system
\end{tabular} & $\begin{array}{l}\text { - Use ferromagnetic brakes to create } \\
\text { an attached magnetic field that moves } \\
\text { with the end-effector }\end{array}$ \\
\hline 5. Wire composition & $\begin{array}{l}\text { (T.C.) Needs combined } \\
\text { materials in complex } \\
\text { shapes yet less } \\
\text { complexity }\end{array}$ & $\begin{array}{l}\text { - Increase } \\
\text { segmentation }\end{array}$ & $\begin{array}{l}\text { - Use off-the-shelf technology from } \\
\text { the electric or lifting industry to } \\
\text { interlace single wires with different } \\
\text { materials. }\end{array}$ \\
\hline $\begin{array}{l}\text { 6. End-Effector } \\
\text { weight }\end{array}$ & $\begin{array}{l}\text { It needs a ticker and yet } \\
\text { light structure }\end{array}$ & \begin{tabular}{|l|} 
- Porous materials \\
- Increase \\
segmentation and \\
dynamism from \\
solid to jointed \\
\end{tabular} & $\begin{array}{l}\text { - Adopt topologic optimisation and } \\
\text { lattice structure made of 3D print } \\
\text { - Segment the wire winding system to } \\
\text { be on the floor. Next, use flexible } \\
\text { shafts to transfer to the end-effector } \\
\text { only the wire. }\end{array}$ \\
\hline $\begin{array}{l}\text { 7. Surface burning } \\
\text { in high-speed } \\
\text { WEDM }\end{array}$ & $\begin{array}{l}\text { (T.C.) Use the entire wire } \\
\text { with no change in } \\
\text { rotation }\end{array}$ & $\begin{array}{l}\text { - Increase } \\
\text { dynamism from } \\
\text { solid to jointed } \\
\text { - Think in time } \\
\text { and scale, and } \\
\text { transfer to the } \\
\text { supersystem } \\
\end{array}$ & $\begin{array}{l}\text { - The wire has its ends precisely } \\
\text { welded, running continuously in the } \\
\text { same direction. } \\
\text { - The robot detects the end of the wire, } \\
\text { stop, move out, revolve } 180^{\circ} \text { and } \\
\text { restart cutting in the same direction. }\end{array}$ \\
\hline $\begin{array}{l}\text { 8. Trade-off SR vs } \\
\text { MRR }\end{array}$ & $\begin{array}{l}\text { (PhC) Needs High } \\
\text { energy pulse for more } \\
\text { MRR at the same } \\
\text { timeless for better SR }\end{array}$ & $\begin{array}{l}\text { - Think in time } \\
\text { and scale to } \\
\text { separate in time }\end{array}$ & $\begin{array}{l}\text { - Pulse generator with higher } \\
\text { frequency removes more material per } \\
\text { time unity yet using lower energy for } \\
\text { better SR }\end{array}$ \\
\hline $\begin{array}{l}\text { 9. Hard to reach the } \\
\text { back of the } \\
\text { workpiece }\end{array}$ & & $\begin{array}{l}\text { - Increase } \\
\text { segmentation and } \\
\text { dynamism, and } \\
\text { separate in time }\end{array}$ & $\begin{array}{l}\text { The additional } 7^{\text {th }} \text { axis acts as a rotating } \\
\text { table and work synchronised with the } \\
\text { robot and allows full access to } \\
\text { workpiece geometry. }\end{array}$ \\
\hline
\end{tabular}




\begin{tabular}{l|l|l|l}
\hline $\begin{array}{l}\text { 10. Hard to flush in a } \\
\text { tilt position }\end{array}$ & $\begin{array}{l}\text { (T.C.) Flow misaligned } \\
\text { with the gravity field }\end{array}$ & $\begin{array}{l}\bullet \text { Blessing in } \\
\text { disguise }\end{array}$ & $\begin{array}{l}\text { Add a nozzle directly into the end- } \\
\text { effector for constant flow-wire } \\
\text { alignment while the robot cuts in a } \\
\text { constant optimum diagonal angle, } \\
\text { always top to bottom. }\end{array}$ \\
\hline
\end{tabular}

Legend: (TC) Technical Contradiction

(PhC) Physical Contradiction (TrE) Trend of Evolution

\subsection{Designed WEDM end-effector}

Following the finding of the TRIZ transdisciplinary approach, , CATIA V5-6 CAD software is adopted, and the system is completely designed. As a proof of concept, the most miniature ABB IRB120 robot system is selected to verify the current robots' ability in coping with WEDM forces and vibrations. The IR payload is only $3 \mathrm{~kg}$ yet delivering nearly $0.7 \mathrm{~m}^{3}$ of working space. Figure 2 depicts the robot.

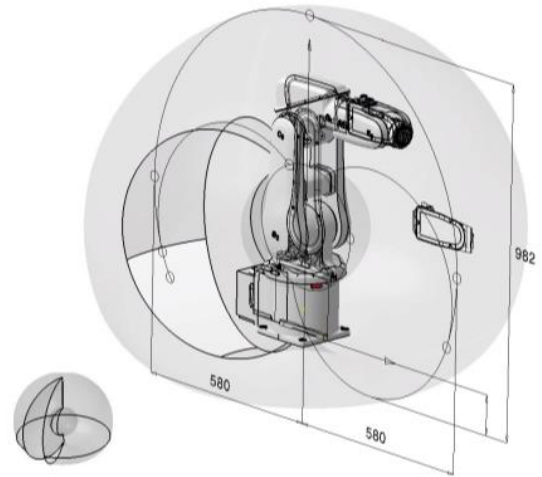

Figure 2. Size and workspace of ABB IRB120 for WEDM combination.

Figure 3 presents the mains subsystem of (1) WEDM end-effector, (2) separated wire winding system, (3) rotating $7^{\text {th }}$ axis table, (4) pulse generator, (5) 6-axis industrial robot.
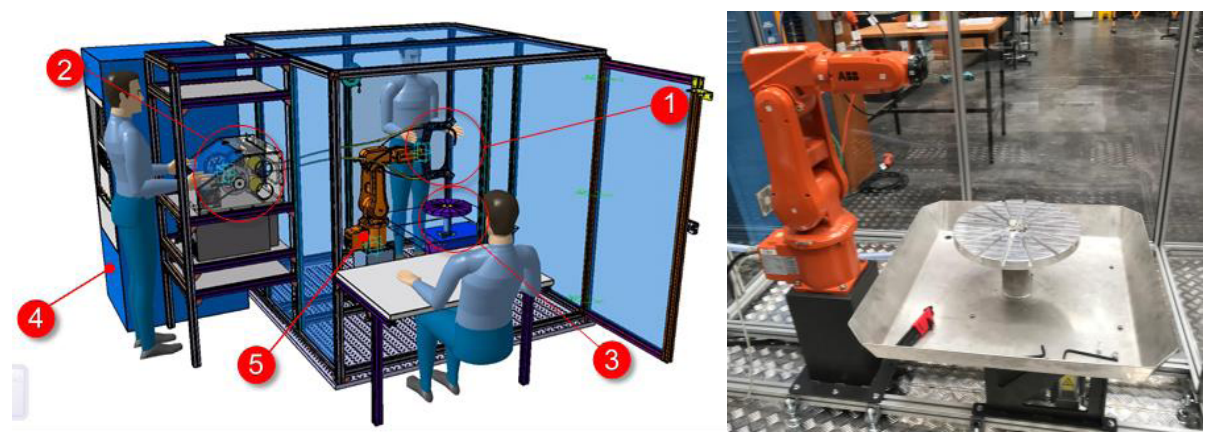

Figure 3. Robotic WEDM cell apparatus and main subsystems.

Next, in Figure 4, balloon 7, 3D-printed nozzles are designed to create a dielectric laminar flow travelling parallel to the wire to go deeper in the kerf for improved flushing. In balloon 6, a dual-axis piezo actuator is used to activate a stationary wave vibration on the wire. Also, it is possible to see the electric brush's use in direct contact 
with the wire providing power and, at the same time, regenerating the wire by filling craters with graphite.

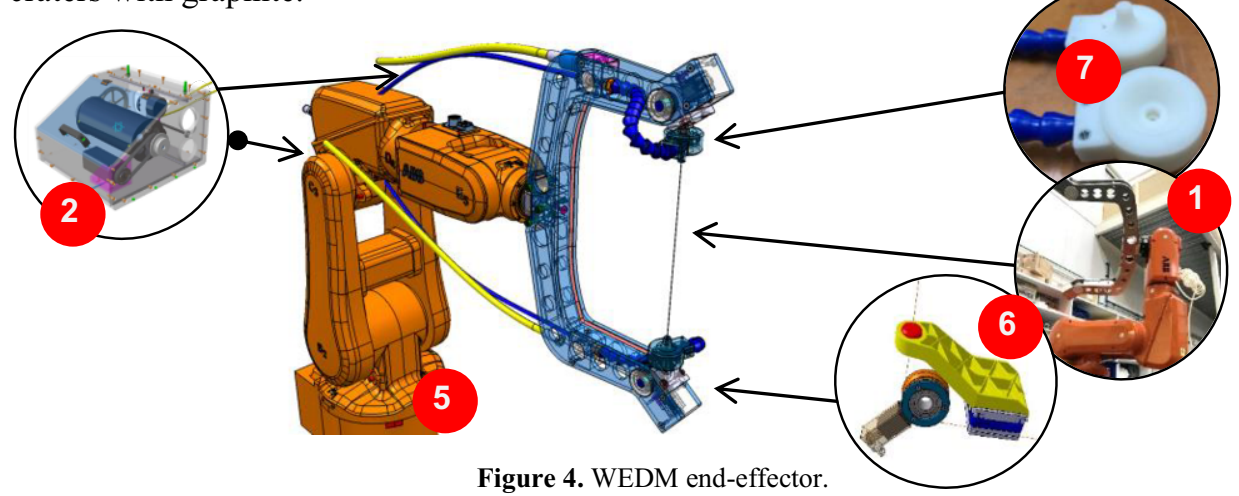

To verify the robotic system's ability to cope with wire EDM vibrations, ANSYS R19 software is used to perform modal harmonic simulation response while the robot is in a pose of low stiffness. It was found that the designed system can perform WEDM and yet avoid harmful vibrations if the pulse frequency is controlled. Figure 5-A displays severe vibration with amplitudes of $27 \mathrm{~mm}$ under the natural frequency of 103 Hz. Figure 5-B shows that the maximal vibration amplitude is found over the wire yet lower than 1 micron when the frequency is above $6 \mathrm{kHz}$.
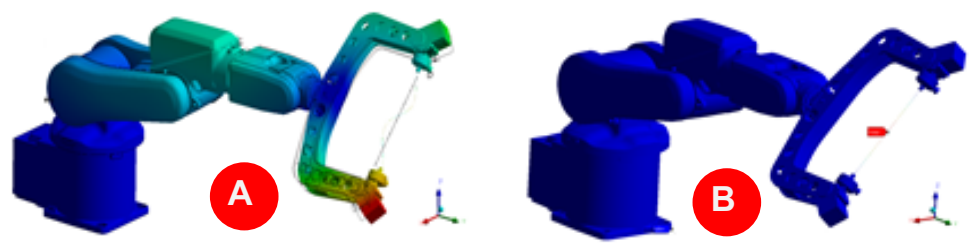

Figure 5. Robotic WEDM vibration response for ABB IRB120.

In Figure 6, a pulse generator with low-intensity iso-energy and pulse frequency up to $1 \mathrm{GHz}$ is prepared.
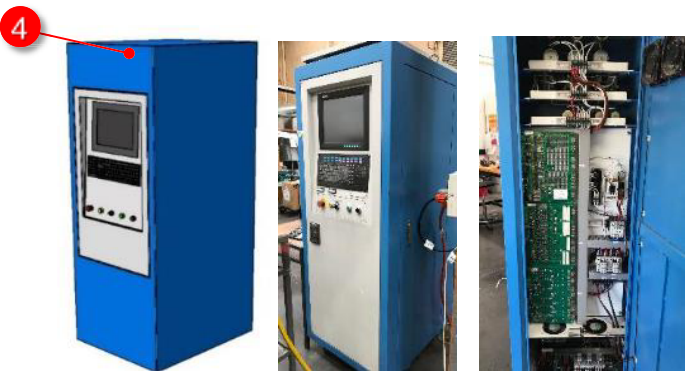

Figure 6. WEDM high-frequency pulse generator.

Although the TRIZ approach has innovative solutions, some ideas have been limited due to the lack of appropriate technologies to put them into the proposed design. For example, no feasible technology to weld a thin wire, yet keeping the external 
diameter (i.e. $0.15 \mathrm{~mm}$ ) was found. The next steps of the present research are to finish building the apparatus and perform a series of experiments to verify the capabilities of robotic WEDM regarding design freedom, vibration, MRR, SR, and precision.

\section{Conclusion}

Traditionally, WEDM has nothing to do with robots due to the nature of the process and structure of the equipment. The idea of combining these two totally different processes creates a series of transdisciplinary problems between mechanical, electronic, manufacturing engineering. There is a lack of prior researches on the challenges of combining these two systems. This paper presents a novel approach to scrutinise robotic and WEDM literature to discover recurrent and new obstacles in system design. TRIZ approach, which has been used extensively for user-oriented product design, is applied to analyse literature. The application of the TRIZ technique in this design process played a key role in finding the best combination and features of the robotic WEDM. The novel adaptation of TRIZ methodology has successfully designed a new combined process system that has the best chance to fulfil the expected system requirements and will deliver two main benefits: first, to cut exotic materials for complex, large, and monolithic workpieces; second, achieving robotic machining free of prohibitive chatter and vibrations, which have been reported to be detrimental to complex robotic compensation, such as backlash, pose, and dumping technics.

\section{References}

[1] K.-H. Park et al., Tool wear in drilling of composite/titanium stacks using carbide and polycrystalline diamond tools, Wear, 2011, Vol. 271, no. 11-12, pp. 2826-2835.

[2] W. Konig, Sparks machine ceramics, Powder Metallurgy International, 1991, Vol. 23, No. 2, pp. 96-100.

[3] A.E.K. Mohammad and D. Wang, A novel mechatronics design of an electrochemical mechanical endeffector for robotic-based surface polishing, in System Integration (SII), 2015 IEEE/SICE International Symposium on, 2015: IEEE, pp. 127-133.

[4] W. Ji and L.H. Wang, Industrial robotic machining: a review, International Journal of Advanced Manufacturing Technology, 2019, Vol. 103, No. 1-4, pp. 1239-1255.

[5] M. Jonsson et al., On force control for assembly and deburring of castings, Production Engineering, 2013. Vol. 7, No. 4, pp. 351-360.

[6] U. Schneider et al., Experimental Investigation of Sources of Error in Robot Machining, Springer, Berlin Heidelberg, 2013.

[7] S. Almeida et al., Strategic Approach to Develop Solutions for Shaping Complex Workpieces of Exotic Materials, IOP Conference Series: Materials Science and Engineering, 2020, Vol. 831, 012003.

[8] G. Cameron, Trizics: Teach yourself TRIZ, how to invent, innovate and solve" impossible" technical problems systematically. Create Space Publishinh Platform, 2010.

[9] W.J.C. Verhagen et al., A critical review of Knowledge-Based Engineering: An identification of research challenges, Advanced Engineering Informatics, 2012, Vol. 26, No. 1, pp. 5-15.

[10]M.-T. Yan, An adaptive control system with self-organizing fuzzy sliding mode control strategy for micro wire-EDM machines, The International Journal of Advanced Manufacturing Technology, 2009, Vol. 50, No. 1-4, pp. 315-328.

[11]S. Singh and M.F. Yeh, Optimization of Abrasive Powder Mixed EDM of Aluminum Matrix Composites with Multiple Responses Using Gray Relational Analysis, Journal of Materials Engineering Performance, 2012, Vol. 21, No. 4, pp. 481-491.

[12]Y.S. Liao et al., On-line Workpiece Height Estimation and its Application in Servo Feed Control of WEDM Process, Procedia CIRP, 2013, Vol. 6, pp. 226-231.

[13]V. Singh and S. Pradhan, Optimization of EDM process parameters: a review, International Journal of Emerging Technology Advanced Engineering, 2014, Vol. 4, No. 3, pp. 345-355. 
[14]A.A. Khan et al., Optimization of Surface Quality of Mild Steel Machined by Wire EDM Using Simulated Annealing Algorithm, in 2015 4th International Conference on Advanced Computer Science Applications and Technologies (ACSAT), 2015, pp. 3-8.

[15]S. Kwon et al., Experimental investigation of the real-time micro-control of the WEDM process, The International Journal of Advanced Manufacturing Technology, 2015, Vol. 79, No. 9-12, pp. 1483-1492.

[16]I. Maher et al., Improve wire EDM performance at different machining parameters - ANFIS modeling, IFAC-PapersOnLine, 2015, Vol. 48, No. 1, pp. 105-110.

[17]B.B. Nayak et al., Parametric Appraisal of WEDM using Harmony Search Algorithm, Materials TodayProceedings, 2015, Vol. 2, No. 4-5, pp. 2562-2568.

[18]L. Zhidong et al., Automatic control of WEDM servo for silicon processing using current pulse probability detection, The International Journal of Advanced Manufacturing Technology, 2014, Vol. 76, No. 1-4, pp. 367-374.

[19]K.T. Hoang and S.-H. Yang, A new approach for Micro-WEDM control based on Real-Time estimation of material removal rate, International Journal of Precision Engineering and Manufacturing, 2015, Vol. 16, no. 2, pp. 241-246.

[20]M. Manjaiah et al., Parametric optimization of MRR and surface roughness in wire electro discharge machining (WEDM) of D2 steel using Taguchi-based utility approach, International Journal of Mechanical and Materials Engineering, 2016, Vol. 11, No. 1, 7.

[21]T. Kamei et al., High-speed Observation of Thin Wire Movement in Fine Wire EDM, Procedia CIRP, 2016, Vol. 42, pp. 596-600.

[22]G.S.B.J. Veerajothi, Experimental Study on Wire Electrical Discharge Machining of Tapered Parts, Arabian Journal for Science and Engineering, 2016, Vol. 41, No. 11, pp. 4431-4439.

[23]W. Wei et al., Surface burning of high-speed reciprocating wire electrical discharge machining under large cutting energy, The International Journal of Advanced Manufacturing Technology, 2016, Vol. 87, No. 9-12, pp. 2713-2720.

[24]S. Habib, Optimization of machining parameters and wire vibration in wire electrical discharge machining process, Mechanics of Advanced Materials and Modern Processes, 2017, Vol. 3, no. 1, 3.

[25]H. Yan et al., Large taper mechanism of HS-WEDM, The International Journal of Advanced Manufacturing Technology, 2016, Vol. 90, No. 9-12, pp. 2969-2977.

[26] V.-M. Nani, The ultrasound effect on technological parameters for increase in performances of W-EDM machines, The International Journal of Advanced Manufacturing Technology, 2016, Vol. 88, No. 1-4, pp. 519-528.

[27]H. Trung Kien, Development of a WEDM system with high machining efficiency, 2017 International Conference on System Science and Engineering (ICSSE), 2017, pp. 397-399.

[28]H. Ciwen et al., Ultra-long Wire Reciprocated-WEDM with Dual Tensile Reels Winded, Procedia CIRP, 2018, Vol. 68, pp. 115-119.

[29]H.M.P. Maity, Predictive Analysis on Responses in WEDM of Titanium Grade 6 Using General Regression Neural Network (GRNN) and Multiple Regression Analysis (MRA), Silicon, 2018, Vol. 10, No. 4, pp. 1763-1776.

$[30] \mathrm{K}$. Mouralova et al., Influence of the cut direction through the semi-finished product on the occurrence of cracks for X210Cr12 steel using WEDM, Archives of Civil and Mechanical Engineering, 2018, Vol. 18, No. 4, pp. 1318-1331.

[31]B.B. Nayak and S.S. Mahapatra, An intelligent approach for prediction of angular error in taper cutting using wire-EDM, Materials Today-Proceedings, 2018, Vol. 5, No. 2, pp. 6121-6127.

[32]K.R. KumarNishasoms, Desirability-Based Multi-objective Optimization and Analysis of WEDM Characteristics of Aluminium (6082)/Tungsten Carbide Composites, Arabian Journal for Science and Engineering, 2019, Vol. 44, No. 2, pp. 893-909.

[33]Z.C.Z.Z. Li, Investigation on a novel surface microstructure wire electrode for improving machining efficiency and surface quality in WEDM, International Journal of Advanced Manufacturing Technology, 2019, Vol. 102, No. 5-8, pp. 2409-2421.

[34]A. Samanta et al., Influence of different control strategies in wire electrical discharge machining of varying height job, The International Journal of Advanced Manufacturing Technology, 2016, Vol. 100, No. 5-8, pp. 1299-1309.

[35]M. Subrahmanyam and T. Nancharaiah, Optimization of process parameters in wire-cut EDM of Inconel 625 using Taguchi's approach, Materials Today: Proceedings, 2020, Vol. 23, pp. 642-646.

[36]E. Abele et al., Prediction of the tool displacement for robot milling applications using coupled models of an industrial robot and removal simulation, Proc. CIRP 2nd Inter Conf on Process Machine Interactions, Vancouver, Canada, 2010.

[37]G.-C. Vosniakos and E. Matsas, Improving feasibility of robotic milling through robot placement optimisation, Robotics and Computer-Integrated Manufacturing, 2010, Vol. 26, No. 5, pp. 517-525. 
[38]J. Pandremenos et al., Machining with robots: a critical review, 7th International Conference on Digital Enterprise Technology, 2011. pp. 1-9.

[39]M. Rippmann and P. Block, New Design and Fabrication Methods for Freeform Stone Vaults Based on Ruled Surfaces, in C. Gengnagel, A. Kilian, N. Palz, and F. Scheurer, (eds.) Computational Design Modelling, Springer, Berlin Heidelberg, 2011, pp. 181-189.

[40]Y.X. Song et al., A method for grinding removal control of a robot belt grinding system, Journal of Intelligent Manufacturing, 2012, Vol. 23, No. 5, pp. 1903-1913.

[41]D. Surdilovic et al., Advanced methods for small batch robotic machining of hard materials, ROBOTIK 2012; 7th German Conference on Robotics, 2012, pp. 1-6.

[42]F. Domroes et al., Application and analysis of force control strategies to deburring and grinding, Modern Mechanical Engineering, 2013, Vol. 3, No. 2, pp. 11-18.

[43]A. Karim and A. Verl, Challenges and obstacles in robot-machining, in IEEE ISR 2013, 2013, pp. 1-4.

[44]S. Keating and N. Oxman, Compound fabrication: A multi-functional robotic platform for digital design and fabrication, (in English), Robotics and Computer-Integrated Manufacturing, 2013. Vol. 29, No. 6, pp. 439-448.

[45]M. Jonsson et al., On force control for assembly and deburring of castings, Production Engineering, 2013, Vol. 7, No. 4, pp. 351-360.

[46]O. Sörnmo et al., High-Accuracy Milling with Industrial Robots using a Piezo-Actuated High-Dynamic Compensation Mechanism, COMET EU/FP7-project, 2013, http://www.cometproject.eu/publications/icra2012.pdf, Accessed July 3, 2021.

[47] S. Caro et al., Workpiece placement optimization for machining operations with industrial robots, 2014 IEEE/ASME International Conference on Advanced Intelligent Mechatronics, 2014, pp. 1716-1721.

[48]I. McLaren and I. Gorlach, Development of a Tool Changer for a Reconfigurable Machine Tool, Applied Mechanics and Materials, 2015, vol. 798, pp. 324-328.

[49]A. Søndergaard et al., Robotic Hot-Blade Cutting, in: D. Reinhardt, R. Saunders, and J. Burry (eds.) Robotic Fabrication in Architecture, Art and Design 2016, Springer International Publishing, Cham, 2016, pp. 150-164.

[50]Y. Bu et al., Stiffness analysis and optimization in robotic drilling application, Precision EngineeringJournal of the International Societies for Precision Engineering and Nanotechnology, 2017, Vol. 49, pp. $388-400$.

[51] M. Jovanovic et al., Robotic fabrication of freeform foam structures with quadrilateral and puzzle shaped panels, Automation in Construction, 2017, Vol. 74, no. Supplement C, pp. 28-38.

[52]Y. Mao et al., Trajectory and Force Generation with Multi-constraints for Robotic Belt Grinding, Springer International Publishing, Cham, 2017.

[53]P. Ruttico, Robots in Architecture, Research and Development, in M. Hemmerling and L. Cocchiarella, (eds.) Informed Architecture, Springer International Publishing, Cham, 2018, pp. 65-76.

[54]A. Søndergaard et al., Robotic abrasive wire cutting of polymerized styrene formwork systems for costeffective realization of topology-optimized concrete structures, Construction Robotics, 2018, Vol. 2, No. 1-4, pp. 81-92.

[55]F. Chen et al., Robotic grinding of a blisk with two degrees of freedom contact force control, (in English), International Journal of Advanced Manufacturing Technology, 2019, Vol. 101, No. 1-4, pp. 461-474.

[56]Y. Ding et al., Research and application on force control of industrial robot polishing concave curved surfaces, Proceedings of the Institution of Mechanical Engineers, Part B: Journal of Engineering Manufacture, 2018, Vol. 233, No. 6, pp. 1674-1686.

[57]T. Cvitanic et al., Pose optimization in robotic machining using static and dynamic stiffness models, Robotics and Computer-Integrated Manufacturing, 2020, Vol. 66, 101992. 